THURSDAY, NOVEMBER 23, I87I

\section{SCIENCE FOR WOMEN}

$\Gamma \mathrm{N}$ the present condition of the two questions of Science 1 Teaching and of the Higher Education of Women, it may be worth while to regard them for a moment from that point of view in which they coalesce, to inquire, in other words, what is being done for the scientific instruction of women. We do not propose now to argue the question whether it is desirable that women should learn science-that we take to be already decided; but rather to speak of the extent to which, at the present time, provision is being made for carrying out this object. The attention of the public was called to the subject a fortnight ago by the publication of the report of the Syndicate appointed by the University of Cambridge for the examination of women above eighteen years of age in July last. The following are the portions of this report which refer to the various subjects coming within our scope :-

"The answers in the present year in Mathematics show a marked improvement upon those in 1870 . The Euclid was decidedly well done, one candidate answering every -question except one rider. The conic sections were tried by only two, and without any great success, nothing being attempted in analytical geometry. The algebra was creditably done, but I observe, as I did last year, that while the candidates are fairly skilled in the management of symbols, they seem to have little idea of a logical proof. I should recommend, in this subject, a much more careful study of proofs of rules. The trigonometry, making allowance for the greater intrinsic difficulty of the subject, was better done than the algebra. Statics, astronomy, and dynamics were taken by very few candidates, one of whom, however, showed a knowledge of these subjects small in amount, but thoroughly sound as far as it went. It may be worth while to remark that one candidate, who took in Euclid and algebra only, was the best in each of these subjects.

"In Botany and Zoology the examiner states that the number of candidates was so small as to give iittle scope for a report. The examination was satisfactory, as far as was possible under the circumstances. One of the candidates passed with distinction. In Geology and Physical Geography the examiner reports as follows:-'No one has done well. The answers are in most cases shallow and full of bad blunders. The examinees seem not to have sufficient acquaintance with the simple laws of physics to make much progress; for instance, it was plain physics to make much progress ; for inary laws of evaporation and condensation of vapour, and it seems to me impossible to understand the causes of clouds and rainfall without such preliminary knowledge. There seemed no better foundation laid in geology. More than one confounded Plutonic with Laurentian rocks. No one showed a tolerable acquaintance with the outlines of systematic a tolerable acquaintance or any knowledge at all of Palaeontology."

The report, though in some respects not unsatisfactory, shows how very much still remains to be done before even a fair start can be said to be made in a general training of our women in the elements of Natural and Physical Science. It is therefore with great pleasure that we welcome the attempts, unconnected and imperfect though some of them may be, which are now being made to remedy this defect.

vol. $\mathrm{v}$.
To place the matter on its right footing, it is essentia that the work should be undertaken by the very best teachers we have at our command; and in London at least this is being done in a manner that must in time bring forth good fruit. The classes for women conducted last season at South Kensington by Professors Huxley, Guthrie, and Oliver were attended by large and highly appreciative audiences; and the programme for the present season, already announced by Professors Duncan, Guthrie, and Huxley, is no less attractive. The Ladies' Educational Association of London has wisely confined its teaching to that of the professors of University College, thus affording a guarantee that the instruction shall be of a first-class kind; and now that the whole scientific staff of the College has placed its services at the disposal of the Association, and the Council has given permission for the lectures to be delivered within its walls, with full use of its philosophical apparatus, a scientific training is for the first time offered to ladies on a par with that obtained by its male students. We learn that the classes named in the programme have all been started, and with a fair number of entries. That there is great room for instruction of this kind is shown also by the eagerness with which women take advantage of the opportunity of attending mixed classes wherever they are conducted by men of high repute. We need only refer to the success which has attended Prof. Huxley's lectures at the London Institution in Finsbury Circus, especially as regards the position taken by girls at the examinations in previous years, and to the crowded audiences, consisting at least half of ladies, who are now attending his course on Elementary Physiology.

In the provinces the same work is going on, though hardly with the same degree of organisation. The professors of the University of Cambridge in particular have shown a praiseworthy zeal in the cause, and have offered their time and their services for a more general system of instruction than could be comprised within the lectures which have been given during the last two years at Cambridge itself. We referred last week to the attempt now being made at the College for Women at Hitchinto be removed, whenever sufficient funds can be obtained, to Cambridge - to inaugurate systematic instruction in Chemistry as an introduction to the other sciences, an attempt to which we heartily wish the success it deserves. When the College for Physical Science was founded at Newcastle, the Council took into consideration a request from a number of ladies of the neighbourhood that women should be admitted to its classes, and decided to make no restriction as to sex in the admission of students or in the rules to which they should be subject. Greatly, however, to the disappointment of the Professors themselves, after all this preparation, when the time came not a single lady presented herself as a pupil. We cannot but think that the ladies of Newcastle were ill-advised in urging the subject upon the Council when there was no actual demand among them for the instruction itself, and thereby giving occasion for unjust reflections on the genuineness of the desire among women for instruction in science.

We wish we could refer with the same satisfaction to the present position of the question in Scotland. The Iadics of Edinburgh have shown their high appreciation of the opportunity that has been offered them by several 
of the Professors of the University for the highest intellectual training, and the Ladies' Educational Association of the Scottish capital has been among the most successful in the kingdom. Emboldened probably by the favour with which the cause of female education was received in Edinburgh, several ladies applied to the University for instruction in a purely medical course of studies; and, the required permission having been obtained, pursued with credit and success the earlier portion of their studies. When they had advanced thus far, however, an unexpected obstacle arose, and the highest governing body of the University, the Senate, stepped in and barred all further progress. The mode, indeed, in which the authorities of the University have played fast and loose with the question of the medical education of women redounds little to their credit. It remains to be seen whether the Council will consent, at the bidding of the Senate, to rescind the regulations which they themselves freely passed in 1869 , with the sanction of the Senate, viz. :-

"Women shall be admitted to the study of medicine in the University. The instruction of women for the profession of medicine shall be conducted in separate classes, confined entirely to women. The professors of the Faculty of Medicine shall, for this purpose, be permitted to have separate classes for women. All women attending such classes shall be subject to all the regulations now or at any future time in force in the University as to the matriculation of students, their attendance on classes, examination, or otherwise."

Any proposal for mixed classes of both sexes in purely medical subjects excites so great a repugnance both among the teachers and students of medicine that it would be extremely unwise to press it; but it will be observed that no such question has been raised here, and no such request has ever been made by the lady medical students The best of the medical as well as the general press of London has been almost unanimous in pointing out the undignified position in which the Senate now stands; and it is earnestly to be hoped that wiser counsels will prevail, and that the University will in future pursue a course which will give greater satisfaction to all its best friends.

We noticed with pleasure the large and comprehensive views expressed by Lord Lyttelton when presiding last week over a meeting of the National Union for Improving the Education of Women of all Classes. Lord Lyttelton's position as Chairman of the Endowed Schools' Commission rendered peculiarly important the opinion he expressed as to the misappropriation of the enormous educational endowments of the country to the benefit of male students only.

The extreme importance to all women, as great if not greater than to men, of an acquaintance with the elements of human physiology and of the laws which govern the body in health and sickness, was admirably set forth in an introductory lecture by Prof. Bennett to his ladies' class at Edinburgh, a portion of which will be found in our present number. The advantage which the community, no less than individuals, will gain when some knowledge of Natural and Physical Science is spread throughout our female population, is so obvious that we have no fear but that the movement now happily inaugurated will spread and prosper in spite of temporary checks and disappointments.

\section{ALLEN'S MAMMALS OF FLORIDA}

On the Mammals and Winter Birds of East Florida: with an Examination of Certain Assumed Specific Characters in Bird Faune of Eastern North America. By J. A. Allen, Cambridge, U.S.A. 187r.

THIS essay forms a portion of the second volume of 1 the "Bulletin of the Museum of Comparative Zoology at Harvard College, Cambridge, Mass.," in which work Prof. Agassiz and his disciples are giving to the world the results arrived at from the study of the rich collections accumulated during the past few years under their charge. Its author is almost new to the particular branch of zoology which he now enters upon, and puts forward his views in a very decided and uncompromising manner. Yet he has obviously taken great pains in the investigations which have conduced to his results, and has, it must be allowed, to a certain extent, proved his point, although, as is usual with most reformers, he has in some cases pushed his theories too far.

Mr. Allen's paper embraces, as he tells us in his Introduction, "five more or less distinct parts." The first contains remarks on the topography, climate, and fauna of Florida, based principally upon observations made during a three months' expedition to that country in the winter of I 868-9. The second portion contains an annotated list of the Mammals of Eastern Florida. In this list some unusual identifications are made-e.g., the Common American Fox (Canis fulvus, auct.) is identified with canis wulpes of Europe, and the American Black Bear (Ursus americanus) is considered inseparable from Ursus arctos. In Part III. we have the reasons which have led the author to adopt these and similar views as to certain species in the class of birds hitherto considered to be distinct put forward at considerable length. The examination of the extensive series of the common North American Birds in the Museum of Comparative Zoology " has disclosed a hitherto unsuspected range of purely individual differentiation in every species thus far studied. . . . Local or geographical variations have been likewise carefully considered, with results that were a short time since unsuspected. . . . These several lines of investigation have shown that in many instances what have been regarded as reliable characteristics of species have in not a few cases little or no value, that the importance of many diagnostic features has been too highly estimated, and that consequently a careful revision of our published faunæ will be necessary for the elimination of the merely nominal species." To all this every true naturalist will give his cordial assent. We are all for reform and revision, when founded on sufficient evidence. But on turning to Part IV. of our author's work, it would appear that some of his identifications have been based on mere conjecture without any evidence at all. For example: Quiscalus brachypterus of Porto Rica and $Q$. crassirostris of Jamaica are placed as synonyms of $Q$. purpureus. Yet it does not appear, or at all events is not stated, that the author has ever examined authentic specimens of the two former species. Again, Chordeiles texercis is united to $C$. popetue without any further remark than that "this widely distributed species presents the usual variations in size and colour." Such and similar errors will, we fear, tend to discredit the identifications which Mr. Allen has 